\title{
THE CURRENT STATE OF CRUSTAL STRESSES IN THE CAUCASUS ACCORDING TO THE UNIFIED CATALOGUE OF EARTHQUAKE FOCAL MECHANISMS
}

\section{Yu.L. Rebetsky}

O.Yu. Schmidt Institute of Physics of the Earth of RAS, Moscow, Russia

\begin{abstract}
The current state of crustal stresses in the Caucasus and adjacent territories has been reconstructed. Stress inversion was performed by the cataclastic analysis of earthquake focal mechanisms considered as seismological strain indicators. The data were taken from the unified catalogue of focal mechanisms of the Northern Eurasia, which was consolidated by the Laboratory of Tectonophysics of IPE RAS in the early 1990s. It contains the information from many seismological data sources of various authors who worked both in the USSR and abroad. Seismological data for the last years after the collapse of the USSR were taken from Global CMT catalogue. The study area has been quite densely covered by reconstructions of the principal stress axes. At the same time, the area of stress averaging has been considerably reduced by the iterative use of a window for stress averaging, which was gradually expanded for zones with reduced densities of earthquake epicenters. The revealed regularities of the current stress field based on the unified catalogue of focal mechanisms collected by different authors correlate with the reconstructions performed according to the Global CMT catalogue. The cataclastic analysis of displacements along fractures allowed estimating the stress magnitudes, and the crust of the study area was zoned with respect to the intensity of normalized values of the lowest and highest stresses of horizontal compression, as well as to the normalized values of shear stresses acting on the crustal basement. In all cases, the values were normalized to the rock strength. The stress parameters are presented in "Tectonic Stresses of Eurasia". This new Internet resource created by the Laboratory of Tectonophysics on the IPE RAS website shows the stress data in different scales and levels of details.
\end{abstract}

KEYWORDS: earthquake focal mechanism; tectonic stress; principal stress axes; stress value

FUNDING: This study was carried out as part of the State Assignment for the Institute of Physics of the Earth of RAS. 


\title{
СОВРЕМЕННОЕ НАПРЯЖЕННОЕ СОСТОЯНИЕ КОРЫ КАВКАЗА ПО ДАННЫМ ОБЪЕДИНЕННОГО КАТАЛОГА МЕХАНИЗМОВ ОЧАГОВ ЗЕМЛЕТРЯСЕНИЙ
}

\author{
Ю.Л. Ребецкий
}

Институт физики Земли им. О.Ю. Шмидта РАН, Москва, Россия

\begin{abstract}
АНнотАЦИЯ. В работе представлены результаты реконструкции современного природного напряженного состояния коры Кавказа и сопредельных территорий. Инверсия напряжений выполнена методом катакластического анализа сейсмологических индикаторов деформаций, которыми являлись данные о механизмах очагов землетрясений. Основу этих данных составлял созданный в лаборатории тектонофизики ИФЗ РАН в начале 90-х гг. прошлого века объединенный каталог механизмов очагов Северной Евразии, который содержал в себе большое число источников сейсмологических данных от различных авторов, работавших не только в СССР, но и за рубежом. Пополнение объединенного каталога сейсмологическими данными за последние после развала СССР годы выполнено на основе каталога Global CMT. Полученные результаты реконструкции осей главных напряжений достаточно плотно по площади покрывают исследуемый регион. При этом удалось существенно уменьшить площадь усреднения напряжений за счет применения итерационного режима подбора окна усреднения напряжений, которое постепенно расширяется для зон пониженной плотности эпицентров землетрясений. Выявленные закономерности поля современных напряжений на основе собранного от разных авторов объединенного каталога механизмов очагов соответствуют также и результатам выполненной реконструкции по данным каталога Global CMT в тех зонах, где они имеются. Поскольку метод катакластического анализа разрывных смещений позволяет оценивать величины напряжений, в работе выполнено районирование коры исследуемого региона по интенсивности нормированных напряжений наименьшего и наибольшего напряжения горизонтального сжатия, а также по нормированной величине поддвиговых касательных напряжений, действующих на подошве коры. Во всех случаях нормировка осуществлялась на прочность сцепления пород. Параметры напряжений в работе представлены с использованием возможностей нового интернет-ресурса «Тектонические напряжения Евразии», который создан сотрудниками лаборатории тектонофизики на сайте ИФЗ РАН. Он позволяет в едином режиме визуализировать данные о напряжениях в разных масштабах и с разной детальностью.
\end{abstract}

КЛЮЧЕВЫЕ СЛОВА: механизм очагов землетрясений; тектоническое напряжение; оси главных напряжений; величина напряжений

ФИНАНСИРОВАНИЕ: Работа выполнена в рамках Госзадания ИФЗ РАН.

\section{1. ВВЕДЕНИЕ}

Южная граница Восточно-Европейской платформы является наиболее сейсмичной ее частью. Горный Кавказ представляет собой ядро этого региона, к которому с целью полноты исследования сейсмического режима следует также отнести сопредельные с ним территории: с запада - Крым и восточную часть Черноморского бассейна, с юга - Восточный Понт, часть Анатолии, горный Эльбурс, с востока - центральную часть Каспийского бассейна, западную часть Копетдага (рис. 1). В недавнем прошлом все эти обширные территории, которые далее мы будем именовать как «регион Кавказ» (РК), были разделены между тремя крупным странами: СССР, Турцией и Ираном. При этом Большой Кавказ и основная часть Малого Кавказа, Крым, северная и центральные части Каспия и Копетдаг входили в СССР. На территориях союзных республик России: Грузии, Армении, Азербайджана, Украины, Туркмении - создавались и успешно функционировали региональные сейсмические сети. Наличие общих институтов политического устройства этих регионов Кавказа позволяло в $1960-$ 1980-х гг. XX в. выполнять комплексы сейсмических наблюдений в рамках близких подходов, достаточно было регулярно обмениваться данными. В эти годы происходило накопление банков данных о землетрясениях, создавались каталоги механизмов их очагов, публиковавшиеся в ведущем сейсмологическом научном журнале «Землетрясения в СССР», были созданы карты общего сейсмического районирования РП-1967, 1978 для части РК. В частности, для территории бывшего СССР общий каталог механизмов очагов землетрясений РК, составленный сотрудниками лаборатории тектонофизики ИФЗ РАН (Г.В. Россанова, А.В. Михайлова) из множества публикаций советских и зарубежных ученых, к моменту распада СССР насчитывал более 700 событий для периода времени до 1992 г. Эти данные вошли в базовый каталог, на основе которого была выполнена реконструкция природных напряжений коры Кавказа и Ирана [Gushchenko et al., 1990, 1991, 1994a] кинематическим методом О.И. Гущенко [Gushchenko, 1981], а затем для юга Азии и Океании [Gushtchenko et al., 1993, 1994b; Rebetsky et al., 1997] соответственно методом О.И. Гущенко и первым вариантом метода катакластического анализа разрывных смещений [Rebetsky, 1996; Rebetskii, 1997].

В настоящее время РК после распада СССР представляют семь стран: Россия, Турция, Иран, Азербайджан, Армения, Грузия, к которым следует также добавить Туркменистан, если иметь в виду сопредельные с этим 


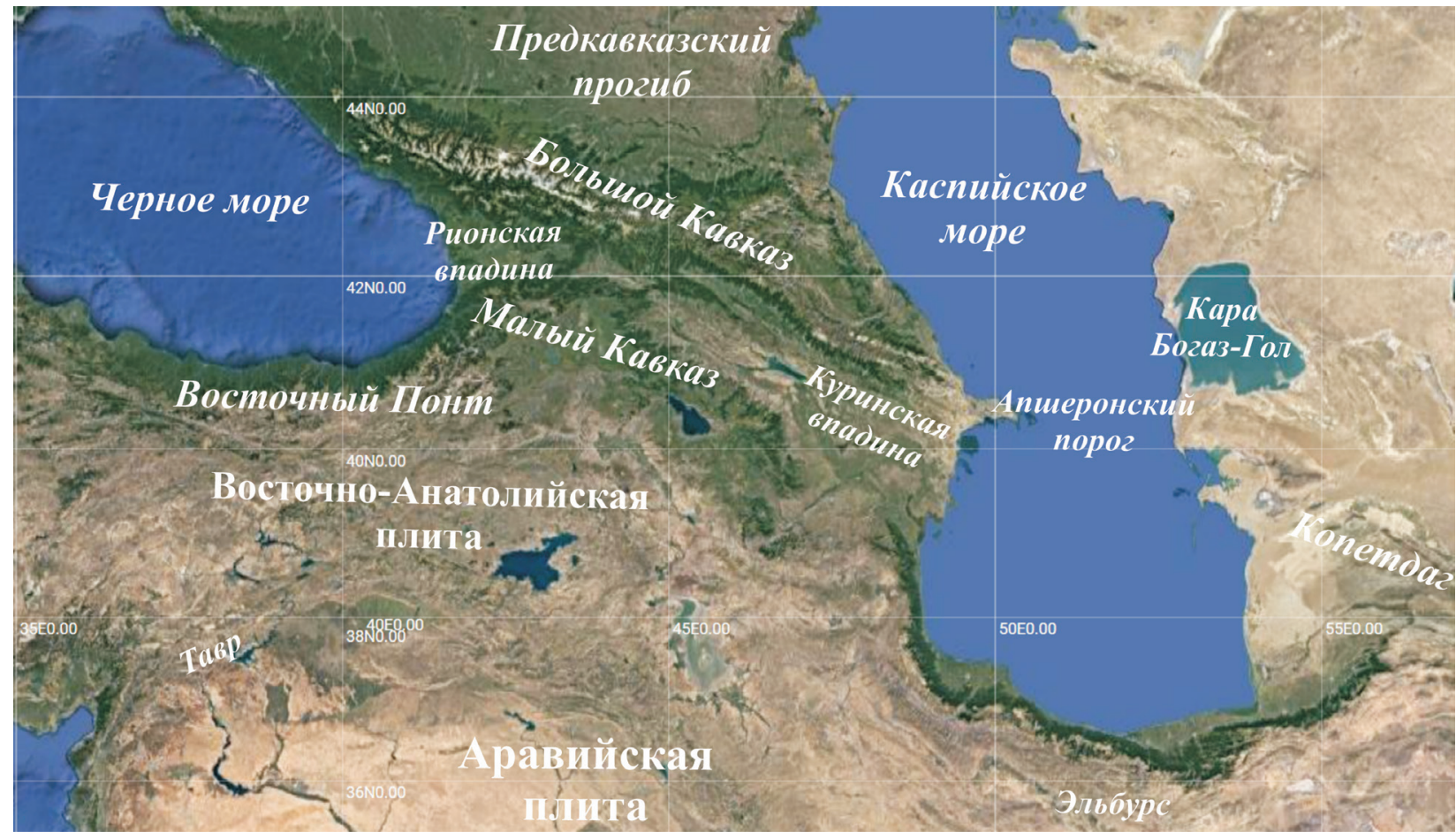

Рис. 1. Карта РК с обозначением тектонических районов.

Fig. 1. The CR Map showing tectonic regions.

регионом восточные территории Центрального Каспия и Копетдага. Прошедшие после распада СССР годы резко изменили ситуацию с пополнением каталога механизмов очагов землетрясений. Нарушились горизонтальные связи между разными группами исследователей, данные региональных сейсмологических наблюдений новообразованных стран перестали публиковаться в открытых изданиях.

Надо отметить, что в последние годы ситуация стала меняться. Начали появляться статьи из стран бывшего СССР, в которых были представлены каталоги не только землетрясений, но и механизмов их очагов [Yetirmishli, Kazimova, 2017, 2018]. Однако это редкое исключение из общего отношения сейсмологов к данным о фокальных решениях. К сожалению, на сайте Российской сейсмологической службы отсутствует даже упоминание о данных тензора сейсмического момента землетрясений. Хорошо известен вклад наших выдающихся сейсмологов (Н.В. Кондорская, В.И. Уломов и др.) в создание и выверку единого каталога землетрясений в СССР. За прошедшие годы сейсмологами так и не был создан единый каталог механизмов очагов землетрясений России и бывшего СССР. По непонятной причине их усилия заканчивались именно на каталогах землетрясений, содержащих только данные о времени, месте и магнитуде землетрясения.

Таким образом, созданный в лаборатории тектонофизики ИФЗ РАН в начале 1990 гг. ХХ в. единый каталог механизмов очагов Северной Евразии, включающий в себя и РК, является уникальным. Однако этот каталог требует специальной предварительной обработки, так как в большинстве случаев по входящим в него событиям разными авторами были получены достаточно сильно различающиеся механизмы очагов.

Хотя многие российские сейсмологи относятся к задаче определения механизмов очагов землетрясений как к некой побочной, вторичной проблеме (главное внимание уделяется определению места, времени и силы событий), следует отметить, что этот тип данных всегда был востребован при решении проблем геодинамики, так как позволял по ориентации осей главных сброшенных напряжений дать первичную информацию о геодинамическом режиме территории [Zoback, 1992]. В настоящее время на основе данных о современном поле ориентации главных тектонических напряжений проводится проверка численных моделей динамической топографии [Bird, 1998; Steinberger et al., 2001; Tutu et al., 2018], в рамках которых осуществляется поиск источника сил движения тектонических плит. В последние годы востребованность данных о природных напряжениях связана также с проблемой сейсмического риска. Понимание этого нашло отражение в работах [Morris et al., 1996; Rebetsky, 2003], в которых были предложены методы оценки кулоновых напряжений на поверхности как крупных региональных разломов [Rebetsky, Kuzikov, 2016], так и небольших разломов и разрывов [Moeck et al., 2008; López, 2012]. После катастрофического Суматро-Андаманского землетрясения одно из направлений прогноза цунамигенных землетрясений стали связывать с данными о механизмах их очагов. Таким образом, актуальность каталогов механизмов очагов землетрясений во всем мире с конца XX в. только возрастает. 


\section{2. ИСХОДНЫЕ СЕЙСМОЛОГИЧЕСКИЕ ДАННЫЕ}

Базисом анализа особенности современного напряженного состояния коры РК являлись сейсмологические данные о механизмах очагов землетрясений каталога, собранного из различных источников сейсмологических данных с 1939 по 1991 г. (594 события) с нижним пределом магнитуд около 2.0 и максимальной магнитудой 7.5. Глубинный диапазон каталога до 60 км.

Этот каталог пополнялся данными механизмов очагов землетрясений из Национального информационного центра землетрясений США (Global CMT), который охватывал период времени с 1976 по 2016 г. и имел нижний магнитудный предел 4.5. Для исследуемого региона имелось 265 событий из каталога Global CMT, произошедших с 1976 по 2016 г. При этом только 68 событий приходилось на период до 1992 г. Таким образом, общее число событий в таком объединенном каталоге составило 759 за период времени с 1939 до конца 2016 г. На рис. 2 показано распределение эпицентров землетрясений из этих каталогов с визуализацией магнитудных диапазонов, глубин и кинематических типов механизмов их очагов.

Известно, что основной проблемой таких объединенных каталогов является наличие многовариантных механизмов очагов отдельных землетрясений, появление которых связано с данными от разных авторов. Такое различие в фокальных механизмах связано не только с различием исходных данных, получаемых с использованием станций глобальной, региональной или локальной сети наблюдений, но и с различием методов обработки самих сейсмических записей. В частности, все механизмы очагов землетрясений, собранные нами в научных публикациях до 1994 г., опирались на фокальные решения, полученные по данным о первых вступлениях сейсмических волн. В то же время данные, привлеченные нами из глобального сейсмологического каталога Global CMT, используют анализ общей волновой картины в фазе сильных движений.

Второй задачей новой реконструкции было получение данных о соотношении сферической и девиаторной компонент тензора напряжений [Rebetsky, 2003], которое позволила сделать новая современная версия МКА. Этот тип данных позволяет спроектировать модель развития деформационного процесса в земной коре. Однако такие новые возможности метода также предъявляют более жесткие требования к каталогу, исключающие многовариантные механизмы очагов землетрясений.

Поскольку с момента предыдущей реконструкции прошло более 20 лет, каталог механизмов очагов землетрясений был дополнен новыми данными, полученными в рамках глобального проекта СМТ (до декабря 2016 г.). Важно отметить, что каталог механизмов за период с 1939 по май 1994 г. был отфильтрован для устранения многовариантных очаговых механизмов землетрясений. Для этого источники данных были ранжированы по степени «надежности» для определения решения фокального механизма землетрясения. В качестве наиболее достоверного вида данных были приняты каталоги фокальных механизмов из базы данных Global СМТ. Слово «надежность» ставится в кавычки, так как этот условный термин имеет мало общего с точностью решений, которые мы получили при расчете. Фокальные механизмы в каталоге Global CMT определяются общей волновой картиной, а все остальные авторы получили свои решения на основе данных о знаках Р-волн. Такие различные подходы объясняют различия в механизмах очагов одних и тех же землетрясений.

В настоящее время невозможно определить, какие источники данных, помимо упомянутых выше, можно считать наиболее надежными, поэтому мы формально исключали варианты фокальных механизмов. Для этого вначале использовали данные из Global CMT для ранжирования других авторов. С этой целью мы проанализировали все решения фокального механизма землетрясения, полученные каждым автором, и сравнили их с решениями Global CMT. Рейтинг авторов зависел от близости их решения и решения Global CMT. Эта процедура являлась первым этапом автоматизированного ранжирования, так как позволяла автоматически получить рейтинг только части авторов каталога, из-за того что каталог Global CMT имел нижний магнитудный предел 4.6 и нижний порог времени 1976 г. Далее, на втором этапе автоматизированного ранжирования, использовались результаты исследований авторов с высоким рейтингом, выявленные на первом этапе. При этом фильтрация не ограничивалась автоматической процедурой, а дополнялась ручной обработкой с использованием статистики многовариантных решений для выбора одного механизма из группы близких решений. Результатом проведенной работы явился каталог механизмов очагов землетрясений с одновариантными решениями. На рис. 2, в, показано распределение кинематических типов фокальных решений землетрясений. Как видно из приведенных данных, эпицентры покрывают исследуемый регион с существенно разной плотностью, что при стандартном алгоритме создания выборок землетрясений должно проявиться в результатах реконструкции (там, где данных мало, реконструкция не будет выполнена). Повышенные глубины очагов землетрясений концентрируются в коре Среднего Каспия и в западной части Копетдага.

Статистический анализ фокальных механизмов показал, что в исследуемом регионе для сборного каталога взбросы составляют $37 \%$, сбросы - $13 \%$, а сдвиги в сочетании со сбросами и взбросами - $41 \%$. Еще 7 \% отвечают переходным механизмам очагов между взбросами и сбросами, которые часто именуют взрезами.

\section{3. О ТЕХНОЛОГИИ РАСЧЕТА НАПРЯЖЕНИЙ И ВИЗУАЛИЗАЦИИ РЕЗУЛЬТАТОВ}

Реконструкция напряжений в глубинном диапазоне 0-60 км и в магнитудном - 3.0-6.5 выполнялась с шагом узлов сетки расчета $0.2^{\circ}$ в два приема для двух каталогов механизмов очагов. В первой реконструкции использовались только решения каталога Global CMT (215 событий). Считалось, что результаты такого расчета, полученные в малом числе точек, наиболее достоверно 


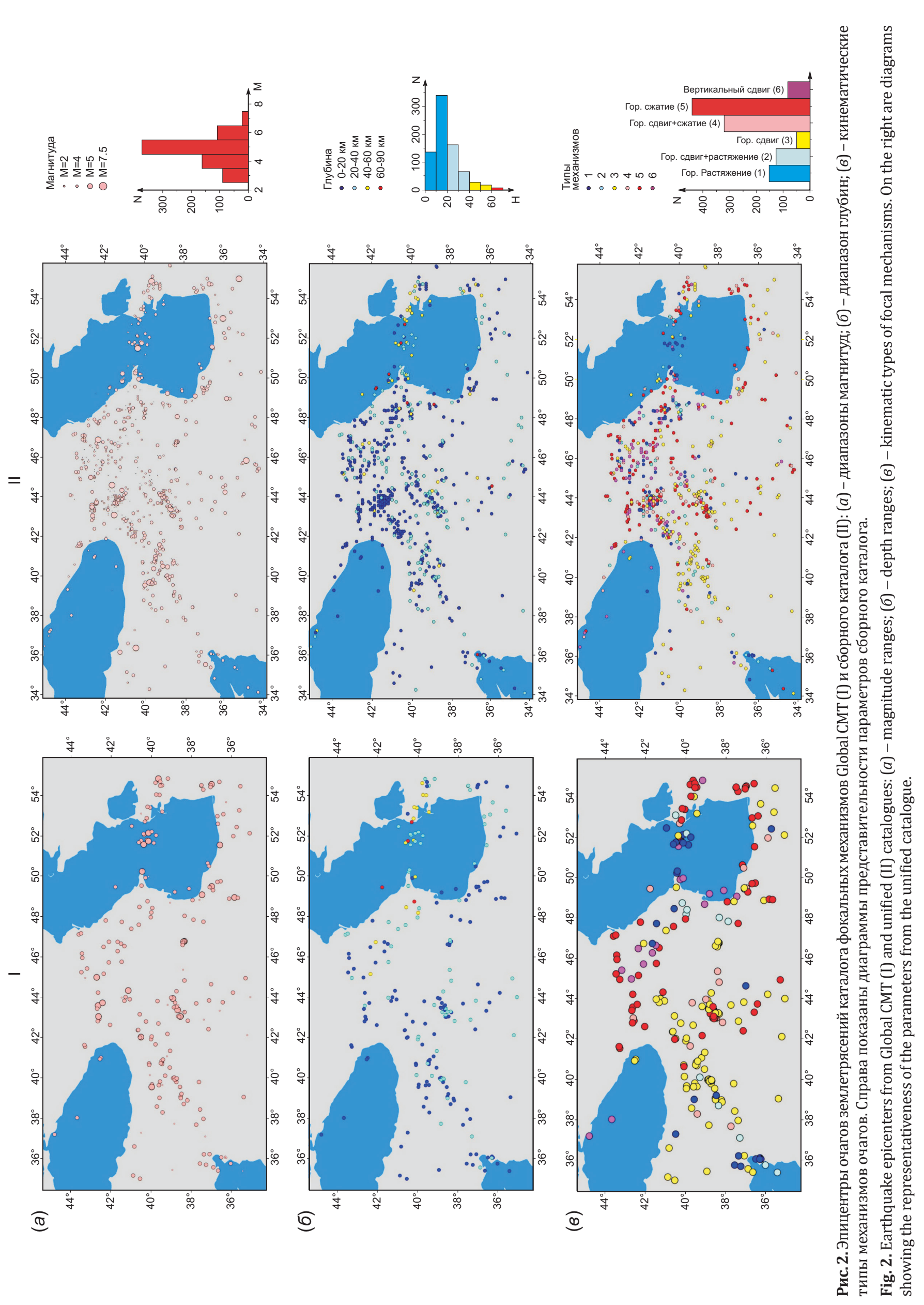


отражают современное напряженное состояние. Во второй реконструкции использовался объединенный каталог одновариантных решений очагов землетрясений, формирование которого описывалось выше. В указанном глубинном и магнитудном диапазоне этот каталог содержал 705 событий.

Поскольку плотность распределения эпицентров очагов землетрясений обоих каталогов была существенно неравномерной, был создан специальный алгоритм формирования начальной выборки землетрясений. Этот алгоритм предусматривал задание максимального окна усреднения около 100 км. Однако в тех случаях, когда вблизи точки расчета напряжений землетрясений было достаточно много, этот алгоритм выполнял расчеты для меньшего окна усреднения. Так, в некоторых узлах сетки были получены данные о напряженных состояниях с усреднением 20-30 км. Во всех случаях начальная выборка землетрясений должна была позволять получить из нее однородную выборку, удовлетворяющую определяющим неравенствам МКА [Rebetsky, 2003], с минимальным числом событий в выборке, равным 5. Специально отметим, что число точек расчета с минимальным числом событий в однородной выборке было очень мало (около 1 \% от общего числа точек расчета).

На рис. 3 показаны узлы сетки, в которых выполнена реконструкция напряжений, с их маркировкой в соответствии с масштабом усреднения напряжений, отвечающих каждому из каталогов. Расчет был выполнен в 643 узлах этой сетки для каталога Global CMT и для объединенного каталога в 1638 узлах сетки.

Далее мы покажем результаты реконструкции с помощью созданного в лаборатории тектонофизики ИФЗ РАН интернет-ресурса «Тектонические напряжения Евразии» [Akhmedov et al., 2015], который сейчас находится в режиме отладки и позволяет визуализировать на карте не только скалярные параметры тензора напряжений, но и векторные параметры: ориентации осей погружения главных напряжений, оси наибольших и наименьших напряжений горизонтального сжатия, направления действия поддвиговых касательных напряжений на горизонтальных площадках.

Для работы на сайте «Тектонические напряжения Евразии» (рис. 4) необходимо использовать адрес http:// shark.ifz.ru. После входа на загрузочную страницу необходимо набрать логин (user) и пароль (1). Далее выбрать "New interface", а потом "Stresses". На главной страничке сайта выбор района визуализации данных о напряжениях происходит в субокне "Files [Stresses]", расположенном у левой границы. Надо поставить галочку напротив нужного вам региона. Затем следует нажать на кнопку «глаз» для «перелета» по карте в нужный регион. Краткое описание возможностей работы с системой представлено на страничке “Stresses".

Выбор параметров напряжений, необходимых для визуализации, происходит в верхнем левом субокне "Select column". Здесь G1, G2, G3 - построение осей главных напряжений $\sigma_{1}, \sigma_{2}$ и $\sigma_{3}$; AZ1, PL1 ....- значения азимутов простирания и углов погружения оси $\sigma_{1} . .$. (и т.д. для $\sigma_{2}$ и $\left.\sigma_{3}\right) ; \mathrm{Mu}$ - коэффициент Лоде - Надаи $\mu_{\sigma}$; IS - геодинамический тип напряженного состояния, Pef $\left(\rho^{*}\right)$ и Tau $(\tau)$ - нормированные на прочность сцепления $\tau_{f}$ соответственно эффективное давление и максимальное касательное напряжение.

Современное состояние системы позволяет быстро и качественно визуализировать данные о напряжениях. Любой пользователь системы может получить графические данные, используя систему Print-Screen для тех данных, которые уже загружены в систему. В дальнейшем предполагается дать возможность пользователям системы загружать в нее свои данные.

\section{4. РЕЗУЛЬТАТЫ РАСЧЕТОВ НАПРЯЖЕНИЙ}

На рис. 5 представлены результаты расчета напряжений для двух каталогов. Показана ориентация осей максимального сжатия, построенного в направлении погружения. Хорошо видно, что оба результата реконструкции успешно совмещаются, т.е. там, где в обоих каталогах они получены, ориентация осей главных напряжений достаточно близка. При этом результаты реконструкции объединенного каталога покрывают в 2.5 раза большую площадь исследуемого региона.

Как следует из роза-диаграмм (вверху справа), характеризующих представительность различных азимутальных направлений осей максмального сжатия $\sigma_{3}$ (рис. $5, a$ ), основным является направление пологого погружения этих осей на юг. Роза-диаграммы наиболее представительных ориентаций азимутов простирания и углов погружения главных напряжений наибольшего сжатия $\sigma_{3}$ и $\sigma_{2}$ также очень похожи. Небольшие различия, связанные с изменением представительности соответственно больших и малых углов погружения, имеют место для главных напряжений $\sigma_{1}$ и $\sigma_{2}$.

Это происходит за счет данных, полученных для восточной части Большого Кавказа, где преобладает субвертикальная ориентация осей $\sigma_{1}$, отличающаяся от субгоризонтальной ориентации на других участках.

Таким образом, результаты сравнения расчетов двух каталогов позволяют говорить о хорошем качестве фильтрации многовариантного каталога механизмов очагов землетрясений, по данным которого был создан объединенный одновариантный каталог.

Для сравнения на рис. 6 представлена ориентация осей напряжений максимального сжатия, полученных из данных проекта WSM. Видно, насколько хаотична не только ориентация простирания погружения осей максимального сжатия (по версиям WSM 1992 и 2008 г., это направление действия максимального горизонтального сжатия), но и само направление погружения. Это особенно проявляется для коры Большого Кавказа и в восточной части Восточной Анатолии.

Напомним, что в рамках трех версий проекта WSM1992, WSM-2008, WSM-2016 [Zoback, 1992; Heidbach et $a l ., 2010,2016]$ существует пять градаций качества расчета ориентации осей главных напряжений. При этом первые три (A, B, C) на самом деле отвечают приемлемой точности определения ориентации главных осей напряжений $\left(\leq 12^{\circ}, \leq 20^{\circ}, \leq 25^{\circ}\right)$. В представленных на 

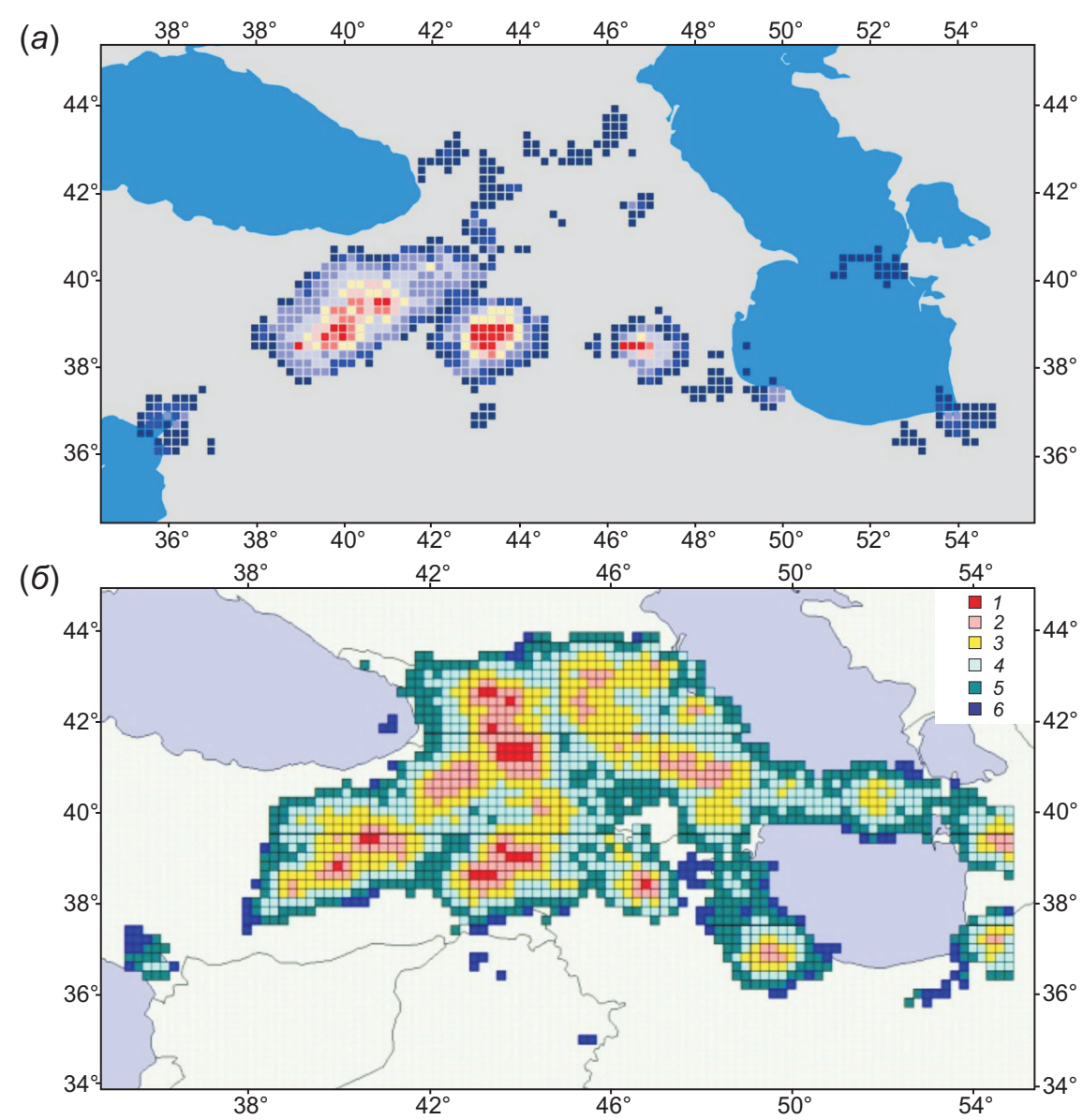

Рис. 3. Узлы сетки, в которых выполнены расчеты с маркировкой цветом (от красного к синему) масштаба усреднения напряжений (см. схему в правом верхнем углу) для: (a) - каталога Global CMT; (б) - сборного каталога.

1-6 - номер итерационного цикла расчета напряжений, приблизительно соответствующий линейному масштабу усреднения $15,30, \ldots 90$ км.

Fig. 3. Calculation grid nodes with colour markers (from red to blue) of the stress averaging scale (see the diagram in the upper right corner) for the Global CMT (a) and unified (6) catalogues.

1-6 - the number of the iterative stress calculation cycle, approximately corresponding to the linear averaging scale of $15,30, \ldots 90 \mathrm{~km}$.

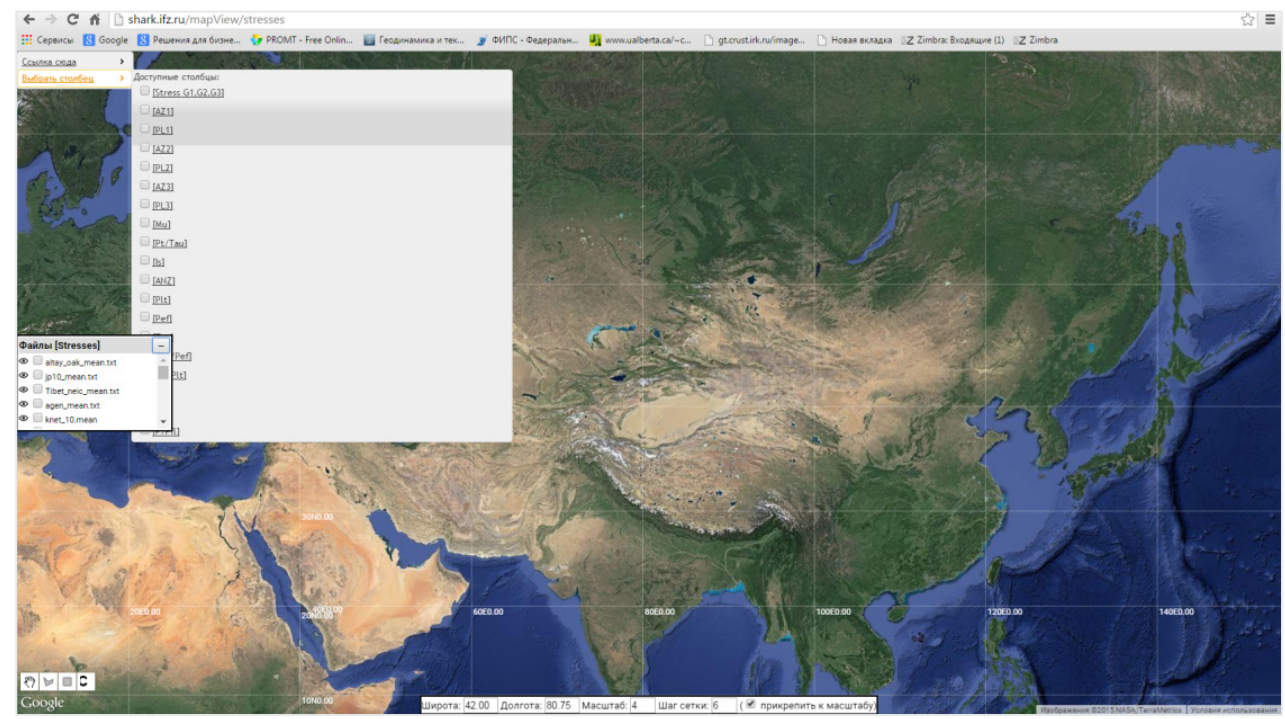

Рис. 4. Главная страница интернет-ресурса «Тектонические напряжения Евразии»: окно загрузки региона с данными о напряжениях (левая граница), окно указания визуализируемых параметров напряжений (верхний левый угол), полоска масштабов и детальность изображения напряженного состояния (нижняя граница).

Fig. 4. The main page of "Tectonic Stresses of Eurasia” Internet resource: a window for loading a region with stress data (left border), a window for specifying visualized stress parameters (upper left corner), a scale bar, and a detailed image of the stress state (lower border). 
(a)
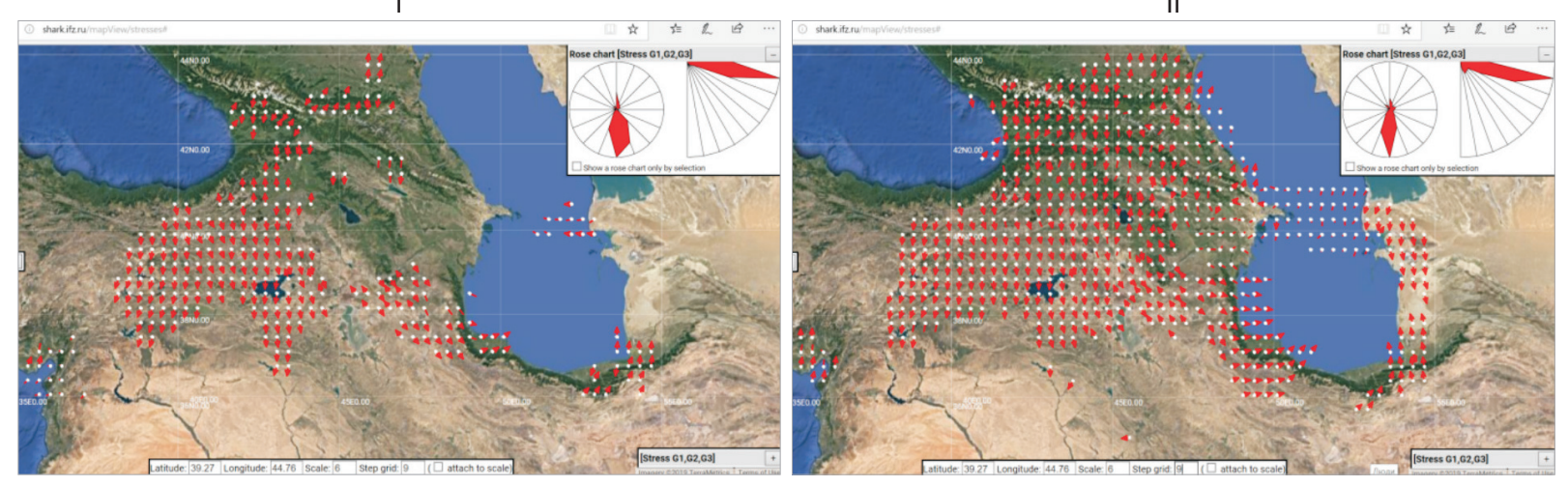

(б)
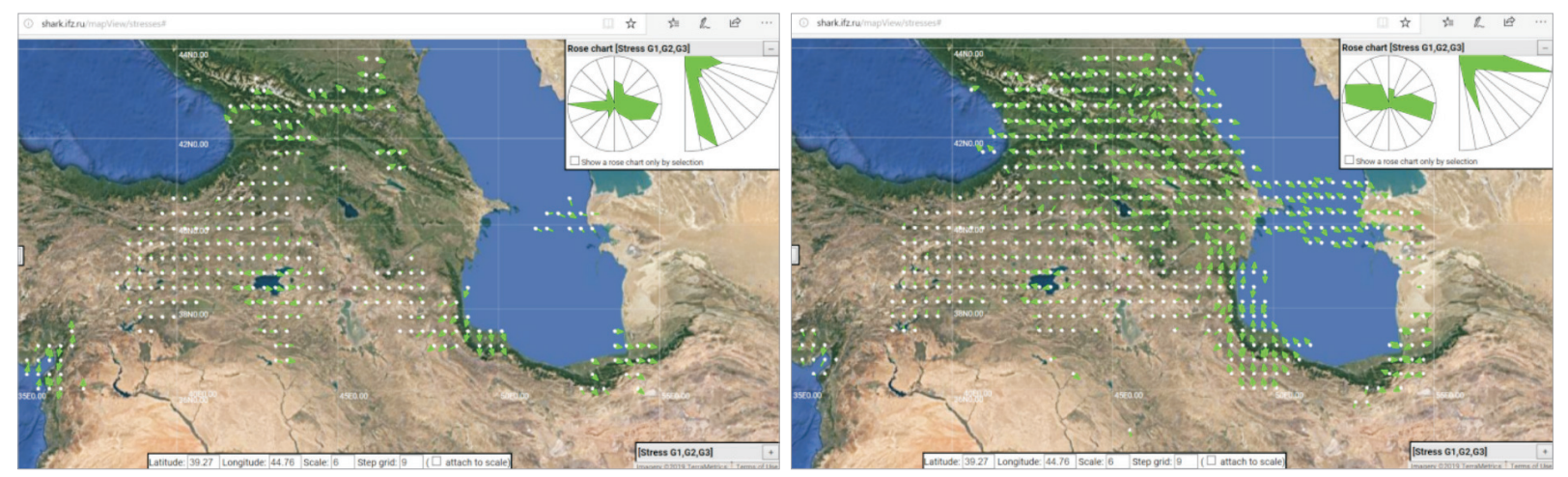

(6)
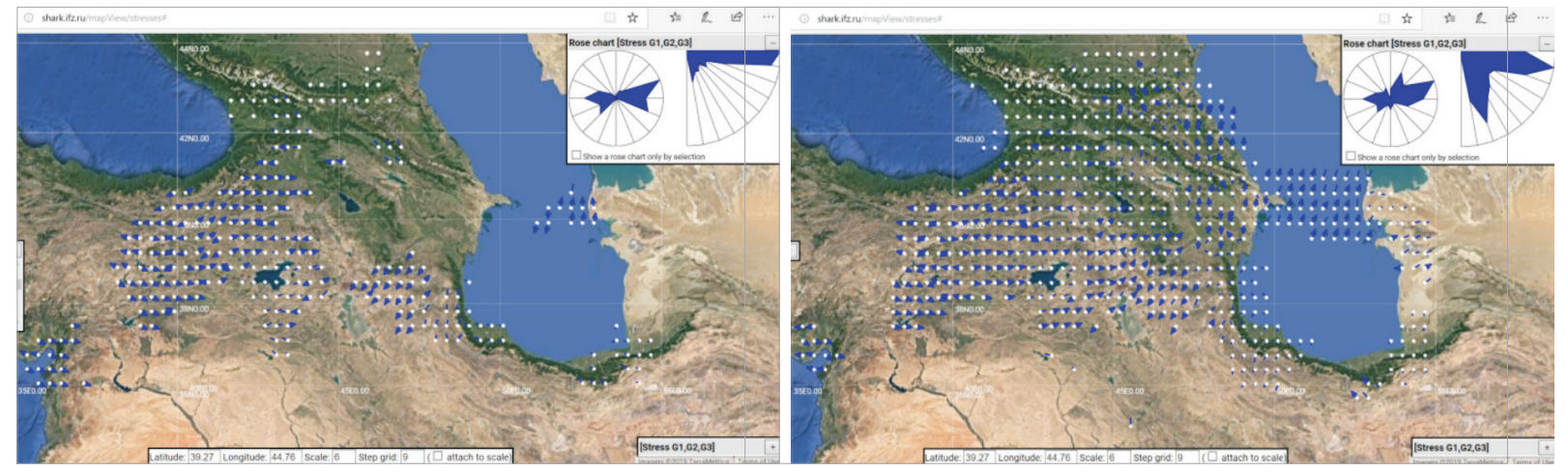

Рис. 5. Ориентация осей главных напряжений: максимального сжатия $\sigma_{3}(a)$, промежуточного главного напряжения $\sigma_{2}(б)$, минимального сжатия - девиаторного растяжения $\sigma_{1}(8)$. I - каталог механизмов очагов Global CMT, II - объединенный каталог механизмов очагов (с данными из Global CMT включительно). Рисунки созданы с использованием интернет-ресурса «Тектонические напряжения Евразии».

Fig. 5. Orientations of the main stress axes: maximum compression $\sigma_{3}(a)$, intermediate main stress $\sigma_{2}(\sigma)$, minimum compression deviatoric extension $\sigma_{1}(\mathrm{~B})$. I - Global CMT catalogue, II - unified catalogue of focal mechanisms (including the data from Global CMT catalogue). The figures are created using "Tectonic Tensions of Eurasia" Internet resource.

рис. 6 результатах (554 точки с данными) только для одной точки реализовано качество В, для 76 \% - качество C, для остальных - качество D и Е. Согласно руководству WSM-2016, качеству С отвечают наиболее хорошо определенные механизмы очага землетрясения в виде двойного диполя с магнитудами $\mathrm{M} \geq 2.5$. Качество А и В соответствует данным, полученным при реализации методов инверсии напряжений из совокупности механизмов очагов для числа событий более 15 и 8 соответственно.

Важно сделать еще одно замечание по поводу изображаемых на картах WSM направлениях «осей напряжений наибольшего горизонтального сжатия» $\mathrm{S}_{\mathrm{H}}$. $\mathrm{C}$ самого начала создания таких карт на них на самом деле изображались проекции на горизонтальную плоскость осей P (для качества C, D и E) или осей наибольшего сжатия (для качества A и В). Только после работы [Lund, Townend, 2007] к авторам проекта пришло понимание того факта, что существует разница между изображением проекций на горизонтальную плоскость осей максимального сжатия и направлениями наибольшего горизонтального сжатия, полученными по правилам тензорного анализа. Однако до сих пор в громадном большинстве случаев на картах WSM изображены именно проекции осей сжатия. Это связано с тем, что для использования при построении осей $S_{\mathrm{H}}$ тензорных формул необходимы не только данные об ориентации главных осей тензора, но и значение коэффициента Лоде - Надаи 


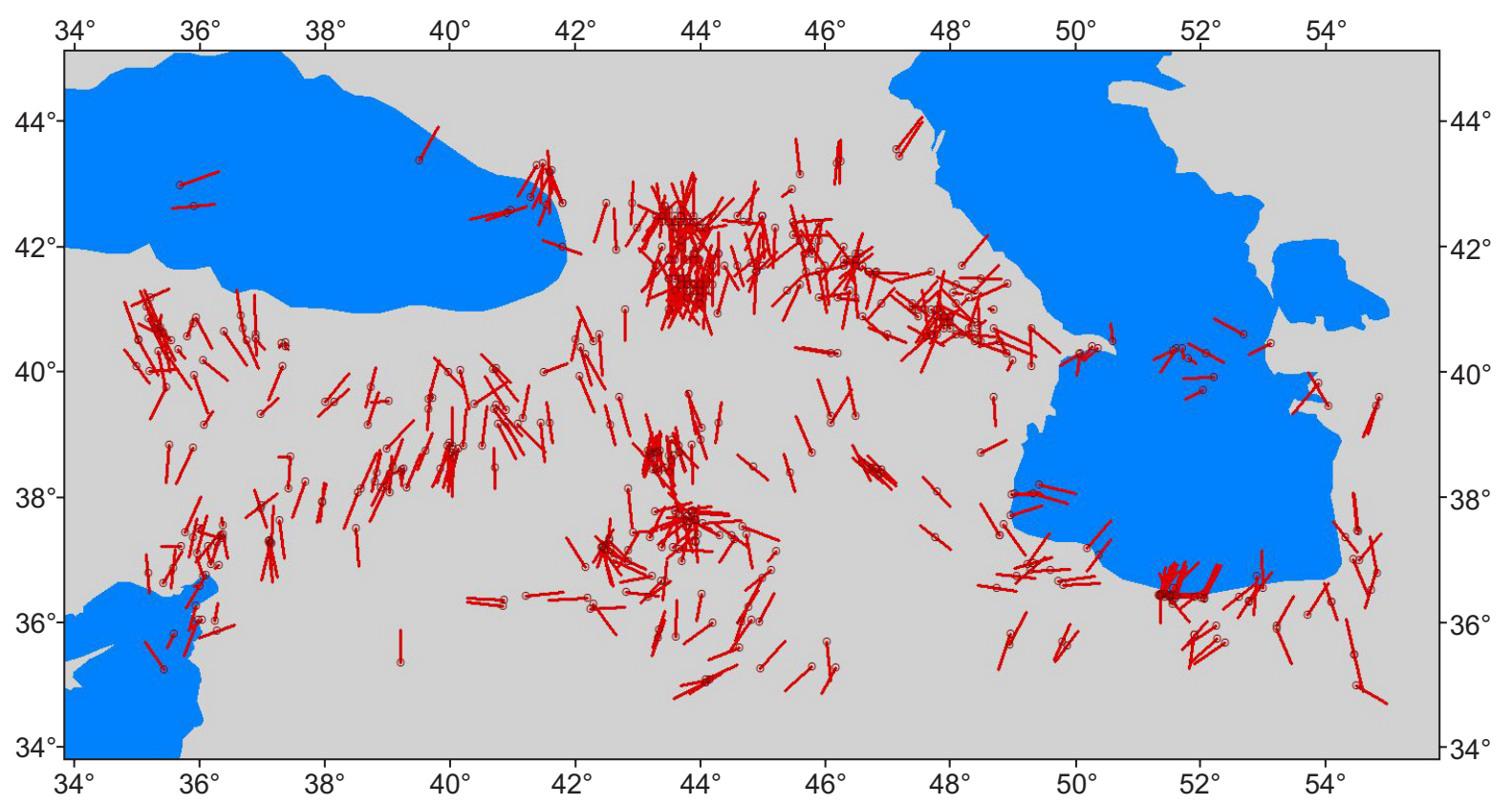

Рис. 6. Карта проекций осей напряжений максимального сжатия, построенных в направлении погружения, по данным проекта WSM-2016.

Fig. 6. Map showing the projections of the maximum compression stress axes constructed in the dip direction (WSM-2016 Project data).

или параметра Ratio, определяющего форму эллипсоида напряжений. Подобного типа данныеможно получить только в методах инверсии напряжений и в решениях для тензора сейсмического момента (СMT).

В том единственном определении качества В, представленном в каталоге WSM для РК, данные о значении параметра Ratio (0.69) присутствовали, однако за направление действия $\mathrm{S}_{\mathrm{H}}$ в базе данных WSM принят азимут оси наибольшего сжатия, т.е. его проекции на горизонтальную плоскость.

Большая часть определений осей, показанных на рис. 6, на самом деле является осями Р, т.е. показывает ориентацию максимального сжатия напряжений, снимаемых в очаге землетрясения. В руководстве WSM2016 указывается на разницу между реальными тектоническими напряжениями, результатом которых явилось землетрясение, и снимаемыми напряжениями в очагах землетрясений. В широко известной работе [McKenzie, 1969] было показано, что реальные оси максимального и минимального сжатия могут располагаться в любой точке квадрантов осей Р и Т соответственно. Даже в случае совпадения плоскости разрыва землетрясения с плоскостью скалывания горных пород отклонение ее ориентации от ориентации осей максимального сжатия тектонических напряжений, отвечающих за разрушение, будет порядка 12-20. При отклонении плоскости разрушения от плоскости скалывания разница в ориентации осей Р, Т и главных осей тектонических напряжений может стать еще больше.

В заключение этого описания системы взглядов, используемой в WSM, укажем на то, что сами авторы данного проекта в руководстве к версии 2016 г. пишут о том, что наивысшим качеством определения осей главных напряжений являются данные о напряжениях, полученные из формализованной инверсии механизмов очагов землетрясений. Именно такой метод и был реализован в нашей статье. Этот метод продолжает работы М.В. Гзовского, Ю.В. Ризниченко, О.И. Гущенко, Б.В. Кострова, С.Л. Юнги.

Анализ ориентации осей главных напряжений (см. рис. 5), полученных по алгоритму МКА, позволяет получить данные о геодинамическом режиме напряженного состояния. Эти данные вместе с результатами расчета параметров эллипсоида напряжений в виде коэффициента Лоде - Надаи представлены на рис. 7. Кора Главного Кавказского хребта в большей части находится в режиме горизонтального сжатия. Только в его восточной части (Дагестан) и к северу от него в области Терско-Каспийского краевого прогиба кроме этого режима также появляются области горизонтального растяжения. Этот режим напряженного состояния продолжается в коре Апшеронского порога Среднего Каспия. В коре Закавказского массива имеет место сочетание горизонтального сжатия и сдвига, которое к востоку в Куринской впадине переходит в горизонтальное растяжение.

Обширные области коры Восточного Понта и Малого Кавказа представлены режимом горизонтального сдвига. Следует отметить, что здесь, в окрестности горного озера Ван, имеет место режим горизонтального сжатия.

Юго-восточная и юго-западная границы Каспия представлены режимом горизонтального сжатия. Западная часть Копетдага проявляется как горизонтальный сдвиг, к северу от которого вновь появляется режим горизонтального сжатия.

В работах тектонофизиков ИФЗ РАН и их последователей при районировании коры по напряженному состоянию использовалась терминология, отличная от той, что применяется в проекте WSM. Вместо взбросового напряженного состояния (inversion fault 
(a)

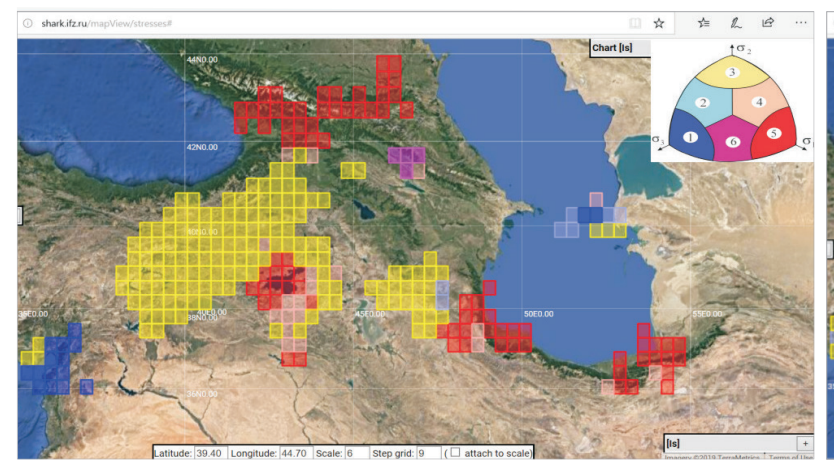

(б)

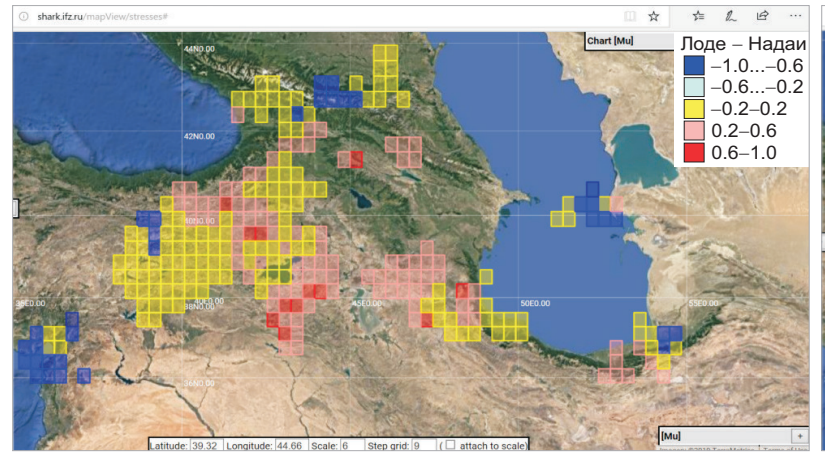

II
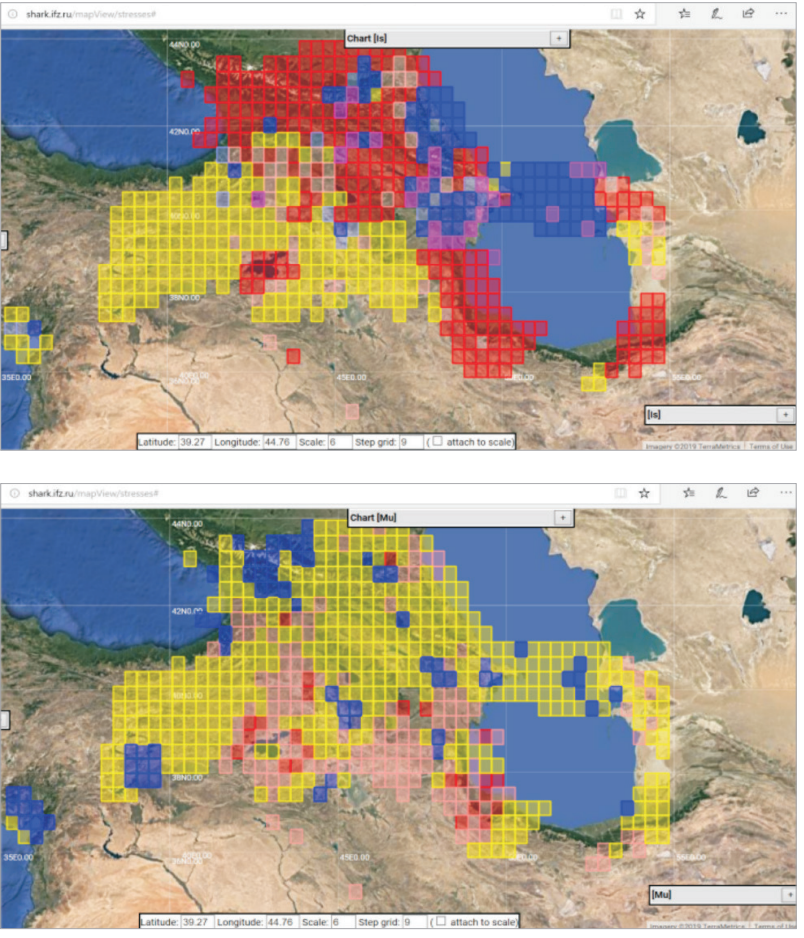

Рис. 7. Районирование региона по геодинамическому типу напряженного состояния $(a)$ и виду эллипсоида напряжений коэффициент Лоде - Надаи (б).

I - каталог механизмов очагов Global CMT, II - объединенный каталог механизмов очагов (с данными из Global CMT включительно). На схеме I, а, в верхнем правом углу показаны геодинамические типы напряженного состояния: 1 - горизонтальное растяжение; 2 - горизонтальное растяжение со сдвигом (transtension); 3 - горизонтальный сдвиг; 4 - горизонтальное сжатие со сдвигом (transpression); 5 - горизонтальное сжатие; 6 - вертикальный сдвиг.

Fig. 7.Zoning of the region by the geodynamic type of stress state (a) and the type of stress ellipsoid - Lode - Nadai coefficient (б). I - Global CMT catalogue, II - unified catalogue of focal mechanisms (including the data from Global CMT catalogue). Geodynamic types of stress state are shown on the scheme I, a, in the upper right corner: 1 - horizontal extension; 2 - horizontal extension with shear (transtension); 3 - horizontal shift; 4 - horizontal compression with shear (transpression); 5 - horizontal compression; 6 - vertical shift.

stress state) мы используем термин «режим горизонтального сжатия», а вместо сбросового напряженного состояния - «режим горизонтального растяжения». Дело в том, что термины «взбросы» и «сбросы» характеризуют кинематику конкретных разломов земной коры, которая, как правило, реализуется при субвертикальной ориентации осей минимального и максимального сжатия соответственно. В курсе механики не существует терминов «сбросовое» или «взбросовое» напряженное состояние. Также можно показать [Rebetskiy. et al., 2017], что из-за предварительного наличия в породах разноориентированных трещин и разрывов их активизация в поле тектонических напряжений может приводить к сосуществованию и взбросов, и сбросов для одной и той же ориентации осей главных напряжений. Таким образом, правильнее напряженное состояние характеризовать по ориентации осей главных напряжений, по отношению к оси на зенит. На самом деле в WSM так и делалось (см. руководство WSM), однако затем участкам с субвертикальной ориентацией осей сжатия и растяжения были присвоены геологические термины.

Значение коэффициента Лоде - Надаи в большей части региона близко к нулю, но также существуют достаточно обширные области отклонения его значений в сторону одноосного сжатия и растяжения, которые в большей мере тяготеют к периферийным участкам исследуемого региона.

На рис. 8, a, показаны ориентации осей наибольшего $\mathrm{S}_{\mathrm{H}}$ и наименьшего $\mathrm{S}_{\mathrm{h}}$ горизонтального сжатия, при этом длина линий этих напряжений отражает их величину. На данном рисунке роза-диаграмма углов погружения на самом деле характеризует представительность напряжений, нормированных на их максимально встречаемую величину (угол $90^{\circ}$ соответствует нулевому значению отношения, а $0^{\circ}$ - максимальному). Наиболее представительным является субмеридиональное направление осей максимального горизонтального сжатия. Максимальные значения горизонтального сжатия наблюдаются в коре центральной части Большого Кавказа, в зоне его перехода к Рионской (на западе) и к Терско-Кумской (на востоке) впадинам. Также высокий уровень этих напряжений имеет место в юго-западном секторе исследуемого региона, вблизи Ливантийского сдвига.

Отметим, что направления этих напряжений рассчитываются в рамках алгоритма метода катакластического анализа согласно правилам работы с тензорами, а не как проекция на горизонтальную плоскость осей 
(a)

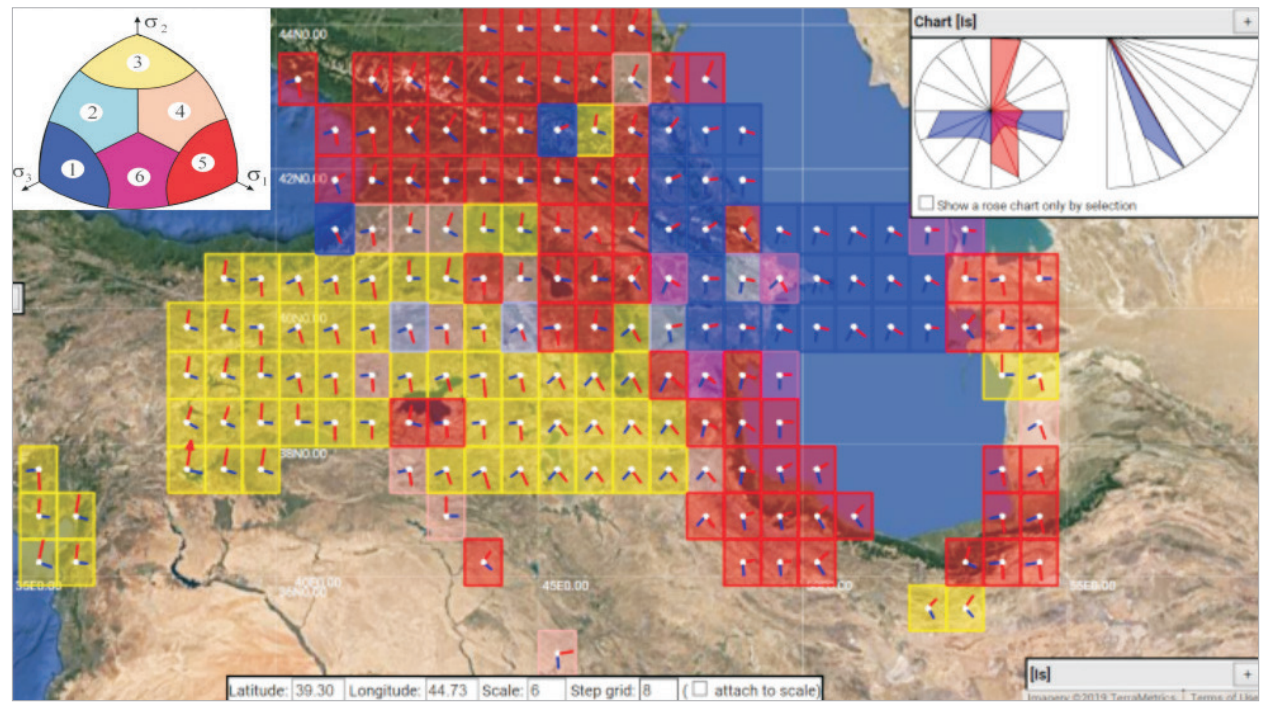

(б)

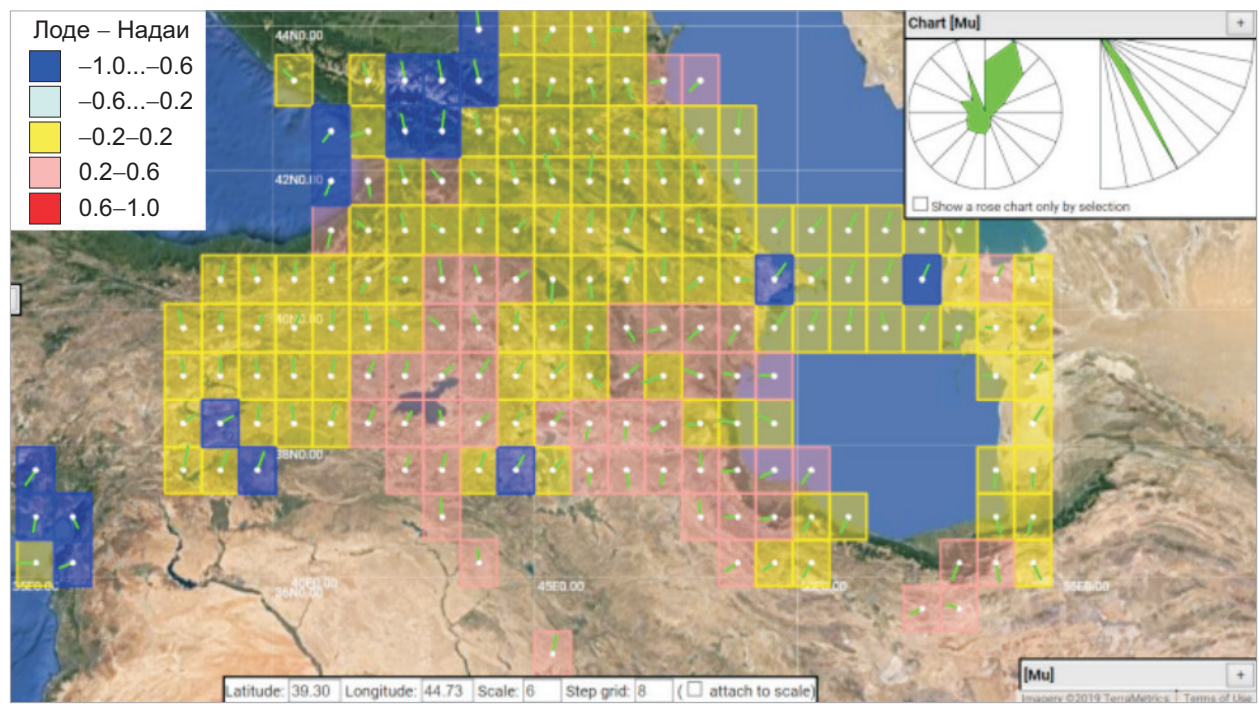

Рис. 8. Районирование региона по данным о результатах расчета по объединенному каталогу механизмов очагов (с данными из Global CMT включительно): (a) - по ориентации осей и величине нормированных напряжений наибольшего SH (красные линии) и наименьшего Sh (синие линии) горизонтального сжатия и типы геодинамического режима напряженного состояния (залитые прямоугольники); (б) - по направлению и нормированной величине (нормировка на прочность сцепления) поддвиговых касательных напряжений и виду эллипсоида напряжений - коэффициент Лоде - Надаи. Интенсивность нормированных напряжений определяется длиной показанных векторов, при этом роза-диаграммы углов погружения (в верхнем правом углу крайние справа диаграммы) отражают наиболее представительные значения относительных величин этих напряжений. См. подписи к рис. 7.

Fig. 8. Zoning of the region based on the calculation results according to the unified catalog of focal mechanisms (including the data from Global CMT catalogue): ( $a$ ) - zoning by orientations of the axes and normalized stress values of the highest SH (red lines) and lowest Sh (blue lines) horizontal compression and the types of geodynamic stress state (filled rectangles); (б) - zoning by directions and normalized values (normalization to rock strength) of underthrust tangential stresses and the type of the stress ellipsoid - Lode Nadai coefficient. The intensity of normalized stresses is determined by vector lengths; the rose diagrams of the dip angles (in the upper right corner, the diagrams on the far right) refer to the most representative relative stress values. See the legend of Fig. 7.

главных напряжений максимального и минимального сжатия [Zoback, 1992]. В нашем случае это возможно, так как уже на первой стадии расчета кроме ориентации осей главных напряжений определяется и вид эллипсоида напряжений, классифицируемый значениями коэффициента Лоде - Надаи.

На рис. 8, б, показано распределение векторов поддвиговых касательных напряжений, действующих на горизонтальных площадках с нормалями вниз. Длина векторов отвечает величине напряжений, нормированной на прочность сцепления. Здесь также роза-диаграмма углов погружения характеризует представительность напряжений, нормированных на максимально встречаемую величину данного напряжения. Наиболее представительным является север - северо-восточное направление поддвиговых касательных напряжений, которое представлено в большом числе точек расчета напряжений. При этом следует обратить внимание на 
тот факт, что к северу от части Большого Кавказа направление этих напряжений противоположное, почти строго на юг. Также отметим, что в коре Большого Кавказа и в ближней к нему зоне эти напряжения имеют наибольший уровень. Другой важной особенностью этих напряжений является их направленность, близкая к радиальной по отношению к береговой линии, в коре Куринской впадины и сопряженной с ней зоне перехода к Южно-Каспийской впадине.

\section{5. ЗАКЛЮЧЕНИЕ}

Созданный в лаборатории тектонофизики ИФЗ РАН в начале 90-х г. XX в. объединенный каталог механизмов очагов Северной Евразии, включающий в себя и РК, является уникальным, так как соединяет в себе множество источников сейсмологических данных. Эти данные прошли проверку на алгоритм МКА, что означает отсутствие в них существенных противоречий друг другу.

Полученные результаты реконструкции напряжений достаточно плотно по площади покрывают исследуемый РК. В нашей новой стресс-реконструкции коры

\section{6. ЛИТЕРАTУРA/REFERENCES}

Akhmedov M.B., Shlyunkin A.V., Luk'yanov I.V., Rebetsky Yu.L., 2015. The field of modern crustal stresses on the IPE RAS site "Global Stress Map". In: Modern tectonophysics. Methods and results. Materials of the Fourth Youth Tectonophysical Workshop (October 5-9, 2015). Vol. 1. IPE RAS, Moscow, p. 16-21 (in Russian) [Ахмедов М.Б., Шлюнкин А.В., Лукьянов И.В., Ребецкий Ю.Л. Поле современных напряжений земной коры на сайте ИФЗ РАН «Global Stress Мар» // Современная тектонофизика. Методы и результаты: Материалы четвертой молодежной тектонофизической школы-семинара (5-9 октября 2015 г.). М.: ИФЗ РАН, 2015. Т. 1. С. 16-21].

Bird P., 1998. Testing hypotheses on plate driving mechanisms with global lithosphere models including topography, thermal structure, and faults. Journal of Geophysical Research: Solid Earth 103 (B5), 10115-10129. https://doi. org/10.1029/98jb00198.

Gushchenko O.I., 1981. Kinematic Method for Determining Stress Parameters and Characteristics of Their Relationships with Tectonic Movements along Discontinuities of Different Structural Levels. Brief PhD Thesis (Candidate of Geology and Mineralogy). Moscow, 21 p. (in Russian) [Гущенко О.И. Кинематический метод определения параметров напряжений и характеристика их связей с тектоническими движениями и по разрывам разных структурных уровней: Автореф. дис. ... канд. геол.-мин. наук. М., 1981. 21 с.].

Gushchenko O.I., Mikhailova A.V., Nikitina E.S., Rebetskiy Yu.L., Lomakin A.A., Arefieva T.P., 1994a. The modern mechanism of crustal deformation in the Caucasus-Iranian seismically active region according to regional stress monitoring and tectonophysical modeling. In: Stresses in the lithosphere (global, regional, and local stresses). Abstracts of the First International Seminar. Moscow, p. 49-50 (in Russian) [Гущенко О.И., Михайлова А.В., Никитина Е.C.,
РК удалось существенно уменьшить площадь усреднения напряжений в большом числе точек их расчета в сравнении с предыдущими реконструкциями напряжений. Это произошло за счет применения итерационного режима подбора окна усреднения напряжений, которое постепенно расширяется для зон пониженной плотности эпицентров землетрясений. Выявленные закономерности поля современных напряжений на основе собранного от разных авторов объединенного каталога механизмов очагов хорошо соответствуют также и данным каталога Global CMT в тех зонах, где они имеются.

Результаты реконструкции напряжений впервые представлены с помощью интернет-ресурса «Тектонические напряжения Евразии», который позволяет в едином режиме визуализировать полученные данные в разных масштабах и с разной детальностью. Этот ресурс создан на Web-сервере ИФЗ РАН в рамках инициативных исследований молодых ученых [Akhmedov et al., 2015] и в настоящее время проходит апробацию в «пилотном режиме».

Ребецкий Ю.Л., Ломакин А.А., Арефьева Т.П. Современный механизм деформирования земной коры КавказоИранской сейсмоактивной области по данным регионального стресс-мониторинга и тектонофизического моделирования // Напряжения в литосфере (глобальные, региональные, локальные): Тезисы докладов первого международного семинара. М., 1994а. С. 49-50].

Gushchenko O.I., Mostryukov A.O., Petrov V.A., 1990. Structure of the modern regional stress field of seismically active regions of the crust in the eastern Mediterranean mobile belt. Doklady AN SSSR 312 (4), 830-835 (in Russian) [Гущенко О.И., Мострюков А.О., Петров В.А. Структура поля современных региональных напряжений сейсмоактивных областей земной коры восточной части средиземноморского подвижного пояса // Доклады АН СССР. 1990. T. 312. № 4. C. 830-835].

Gushchenko O.I., Rebetsky Yu.L. , Mikhailova A.V., Rossanova G.V., Le Min Quoc, Fursova E.V., 1994b. The modern regionalstress field of Eurasia (from seismological data on crustal earthquake focal mechanisms). In: Stresses in the lithosphere (global, regional, and local stresses). Abstracts of the First International Seminar. Moscow, p. 50-51 (in Russian) [Гущенко О.И., Ребецкий Ю.Л., Михайлова А.В., Россанова Г.В., Ле Минь Куок, Фурсова Е.В. Современное региональное поле напряжений Евразии (по сейсмологическим данным о механизмах очагов коровых землетрясений) // Тезисы докладов первого международного семинара: Напряжения в литосфере (глобальные, региональные, локальные). М.: Изд-во ИГиРГИ, 1994б. C. 50-51].

Gushchenko O.H., Rebetsky Yu.L., Mikhailova A.A., Rossanova G.V., Lomakin A.A., Arefieva T.P., 1991. Regional stress monitoring and the crustal deformation mechanism in the Caucasus-Iran seismically active region. In: The mechanics of structure formation in the lithosphere and seismicity. IPE RAS, Moscow, p. 165-166 (in Russian) [Гущенко О.И., 
Ребецкий Ю.Л., Михайлова А.В., Россанова Г.В., Ломакин А.А., Арефьева Т.П. Региональный стресс-мониторинг и механизм деформирования земной коры Кавказо-Иранской сейсмоактивной области // Механика структурообразования в литосфере и сейсмичность. М.: ИФЗ РАН, 1991. С. 165-166].

Gushtchenko O.I., Rebetsky Y.L., Mikhailova A.V., Gushtchenko N.Y., Kuok L.M., Rassanova G.V., 1993. The recent regional field of stresses and the mechanism of the lithosphere deformation of seismoactive East-Asia region. Terra Nova 5 (1), 259.

Heidbach O., Rajabi M., Reiter K., Ziegler M., WSM Team, 2016. World Stress Map Database Release 2016. GFZ Data Services. https://doi.org/10.5880/WSM.2016.001.

Heidbach O., Tingay M., Barth A., Reinecker J., Kurfe D., Müller B., 2010. Global crustal stress pattern based on the World Stress Map database release 2008. Tectonophysics 482 (1-4), 3-15. https://doi.org/10.1016/j.tecto.2009.07.023.

López A., 2012. Andersonian and Coulomb stresses in Central Costa Rica and its fault slip tendency potential: new insights into their associated seismic hazard. Geological Society, London, Special Publications 367, 19-38. https:// doi.org/10.1144/SP367.3.

Lund B., Townend J., 2007. Calculating horizontal stress orientations with full or partial knowledge of the tectonic stress tensor. Geophysical Journal International 170 (3), 13281335. https://doi.org/10.1111/j.1365-246X.2007.03468.x.

McKenzie D.P., 1969. The relation between fault plane solutions for earthquakes and the directions of the principal stresses. Bulletin of the Seismological Society of America 59 (2), 591-601.

Moeck I., Schandelmeier H., Holl H.-G., 2008. The stress regime in a Rotliegend reservoir of the Northeast German Basin. International Journal of Earth Sciences 98 (7), 16431654. https://doi.org/10.1007/s00531-008-0316-1.

Morris A.P., Ferrill D.A., Henderson D.B., 1996. Slip tendency analysis and fault reactivation. Geology 24 (3), 275-278. https://doi.org/10.1130/0091-7613(1996)024<0275:ST AAFR>2.3.CO;2.

Rebetskii Yu.L., 1997. Reconstruction of tectonic stresses and seismotectonic strain: Methodical fundamentals, current stress field of Southeastern Asia and Oceania. Translation (Doklady) of the Russian Academy of Science. Earth Science Sections 354 (4), 560-563.

Rebetsky Yu.L., 1996. I. Stress-monitoring: Issues of reconstruction methods of tectonic stresses and seismotectonic deformations. Journal of Earthquake Prediction Research 5 (4), 557-573.
Rebetsky Yu.L., 2003. Stress-strain State and Mechanical Properties of Natural Massifs According to the Data on the Earthquake Focal Mechanisms and Structural-Kinematic Characteristics of Fractures. PhD Thesis (Doctor of Physics and Mathematics). UIPE RAS, Moscow, 455 p. (in Russian) [Ребецкий Ю.Л. Напряженно-деформированное состояние и механические свойства природных массивов по данным о механизмах очагов землетрясений и структурно-кинематическим характеристикам трещин: Дис. ... докт. физ.-мат. наук. М.: ОИФЗ РАН, 2003. 455 с.].

Rebetsky Yu.L., Kuzikov S.I., 2016. Active faults of the northern Tien Shan: tectonophysical zoning of seismic risk. Russian Geology and Geophysics 57 (6), 967-983. https:// doi.org/10.1016/j.rgg.2016.05.004.

Rebetsky Yu.L., Mikhailova A.V, Rosanova G.V, Fursova E.V., 1997. II. Stress-monitoring: The modern field of regional stresses in South-East Asia and Oceania. Principles of quasiplastic deforming of fractured media. Journal of Earthquake Prediction Research 6 (1), 11-36.

Rebetskiy Yu.L., Sim L.A., Marinin A.V., 2017. From slickensides to tectonic stresses. Methods and algorithms. GEOS, Moscow, 234 c. (in Russian) [Ребецкий Ю.Л., Сим Л.А., Маринин А.В. От зеркал скольжения к тектоническим напряжениям. Методики и алгоритмы. М.: ГЕОС, 2017. 234 c.].

Steinberger B., Schmeling H., Marquart G., 2001. Largescale lithospheric stress field and topography induced by global mantle circulation. Earth and Planetary Science Letters 186 (1), 75-91. https://doi.org/10.1016/S0012821X(01)00229-1.

Tutu A.O., Steinberger B., Sobolev S.V., Rogozhina I., Popov A.A., 2018. Effects of upper mantle heterogeneities on lithospheric stress field and dynamic topography. Solid Earth 9 (3), 649-668. https://doi.org/10.5194/se-9-649-2018.

Yetirmishli G.J., Kazimova S.E., 2017. Types of tectonic movements of the seismogenic areas of Azerbaijan based on the earthquake focal zones. Geological-geophysical studies of the deep structure of the Caucasus. In: Geology and Geophysics of Caucasus. Vladikavkaz, p. 20-25.

Yetirmishli G.J., Kazimova S.E., 2018. Focal mechanisms of earthquakes and stress field of the earth crust in Azerbaijan. In: D'Amico S. (Ed.), Moment tensor solutions: a useful tool for seismotectonics. Springer, Cham, p. 481-495. https:// doi.org/10.1007/978-3-319-77359-9_21.

Zoback M.L., 1992. First-and second-order patterns of stress in the lithosphere: The World Stress Map Project. Journal of Geophysical Research: Solid Earth 97 (B8), 11, 703-11728. https://doi.org/10.1029/92JB00132.

\section{YURI L. REBETSKY}

Doctor of Physics and Mathematics, Head of Laboratory O.Yu. Schmidt Institute of Physics of the Earth, RAS

10 Bol'shaya Gruzinskaya St, Moscow D-242 123995,

GSP-5, Russia

e-mail: reb@ifz.ru

ORCID: 0000-0003-3492-2452

\section{ЮРИЙ ЛЕОНИДОВИЧ РЕБЕЦКИЙ}

докт. физ.-мат. наук, зав. лабораторией Институт физики Земли им. О.Ю. Шмидта РАН 123995, ГСП-5, Москва Д-242, ул. Большая Грузинская, 10 , Россия 